\title{
Male Malignant Nipple Neoplasm
}

National Cancer Institute

\section{Source}

National Cancer Institute. Male Malignant Nipple Neoplasm. NCI Thesaurus. Code C120454.

A malignant neoplasm that affects the area of the nipple in males. 